\title{
La comunión, dinamismo soteriológico de Cristo en Ef 1, 3-6
}

\author{
Communion, soteriological dynamism \\ of Christ in Eph 1, 3-6
}

Joseph Théophile Ngouo, M.S.A.

\section{Resumo}

Nesta pesquisa, trata-se de conhecer a mensagem salvífica presente em Ef 1, 3-6. Esta preocupação encontra-se no coração do texto bíblico como mensagem de salvação y do Método Semântico Teológico utilizado para esta análise, que pretende encontrar no texto bíblico o núcleo do cristianismo: a experiência salvífica de Cristo acontecendo na vida do crente. Foram identificados os dinamismos salvíficos de Cristo significados por campos semânticos que relacionam e explicitam o tecido textual, evidenciando os elementos linguísticos e filológicos essenciais para a compreensão do texto. O novo olhar proporcionado pelo Método Semântico Teológico nos ofereceu resultados novos e enriquecedores para a vivência da mensagem de salvação. De modo geral, na Carta aos Efésios, identificam-se 75 dinamismos salvíficos de Cristo e 86 campos semânticos dos quais a comunhão com Cristo abarca a totalidade da carta e se apresenta como fio condutor e elemento fundamental do acontecer salvífico de Deus na pessoa de Cristo para a comunidade cristã. 11 dinamismos salvíficos e 28 campos semânticos são identificados no Hino e 4 dinamismos com 7 campos identificados no texto de nosso estudo. A

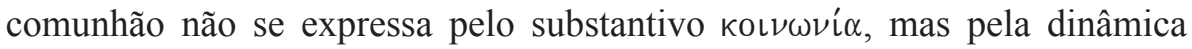
preposicional. A comunhão se entrelaça com distintos campos e apresenta no texto o seu conteúdo e mensagem teológica.

Palavras-chave: Dinamismos salvíficos, Campos semânticos, Comunhão, preposições. 


\section{Resumen}

En esta Investigación, se trata de conocer el mensaje salvífico contenido en el Himno de la Carta a los Efesios. Este problema se encuentra en el corazón del texto bíblico, como mensaje de salvación, y del Método Semántico Teológico del Nuevo Testamento, empleado en esta Monografía, que pretende encontrar en el texto el núcleo vital del cristianismo: la experiencia salvífica de Cristo aconteciendo en la vida del creyente. Fueron identificadas los dinamismos salvíficos de Cristo significados por Campos Semánticos que relacionan y explicitan el tejido textual, evidenciando los elementos lingüísticos y filológicos esenciales para la comprensión del texto. Esta "nueva mirada" nos brindó resultados novedosos y enriquecedores para la vivencia del mensaje salvífico: En la Carta, se encuentran 75 acciones soteriológicas de Cristo. Identificamos 86 campos semánticos de los cuales la comunión en y con Cristo abarca la totalidad de la Carta y se presenta como su hilo conductor y elemento fundamental del acontecer salvífico de Dios en la persona de Cristo para la comunidad creyente. El campo de la comunión no se expresa con el sustantivo коเ $\nu \omega \nu i \alpha$, sino que es dinamizada por preposiciones. La comunión se entreteje con distintos campos en cada sección del texto dando la posibilidad de 'contemplar' su contenido y mensaje teológico.

Palabras-clave: Dinamismos salvíficos, Campos semánticos, Comunión, preposiciones.

\section{Abstract}

The present study tries to know the salvific message of Eph 1, 3-6. This concern is the heart of the biblical text as salvation's message and the Semantic Theological Method used for the analysis that interest is finding in the biblical text the core message of Christianity: the salvific experience of Christ happening in the life of the believer. Christ salvific dynamisms signified by semantic fields that relate and explain the textual fabric were be identified; highlighting the essential philological and linguistic elements to the understanding of the text. The new look provided by Semantic Theological Method offered us new and enriching results for the real life of the salvation's message. In general, in the Letter to the Ephesians, we identified 75 salvific dynamisms of Christ and 86 semantic fields whose communion with Christ embraces the whole letter and introduces 
himself as conductor and fundamental element of God's salvific happening in Christ for Christian community; 11 salvific dynamisms and 28 semantic fields were identified in the hymn and 4 salvific dynamisms and 7 semantic fields were identified in our text (Eph 1,3-6). The communion is not expressed by the noun $\kappa o \iota \nu \omega \nu i \alpha$ but by the prepositional dynamic. The communion is intertwined with distinct semantic fields showing in the text its content and theological message.

Keywords: salvific dynamisms, semantic fields, communion, prepositions.

\section{Introducción}

La Sagrada Escritura ha sido a través de los siglos un lugar impresionante de investigación. En el transcurso de los años y con el impulso efectivo del Concilio Vaticano II, la manera de leer e interpretar la Escritura se ha ido transformando. Al reconocer y valorar los logros de los distintos métodos de interpretación bíblica, destacamos de manera especial la importancia del Método Semántico Teológico, cuyo dinamismo nos conduce al núcleo vital del cristianismo: la experiencia salvífica de Dios en la persona de Jesucristo aconteciendo en la vida del creyente. La Pontificia Comisión Bíblica reconoce que "la interpretación de la Sagrada Escritura es de importancia capital para la fe cristiana y la vida de la Iglesia (...) el modo de interpretar los textos bíblicos para los hombres y las mujeres de nuestro tiempo tiene consecuencias directas para su relación personal y comunitaria con Dios, y también está ligado estrechamente a la misión de la Iglesia. Se trata de un problema vital"'. Para la presente investigación, optamos por el Método Semántico Teológico ${ }^{2}$ que consiste esencialmente en evidenciar y analizar los dinamismos soteriológicos presentes en nuestra perícope como elementos fundamentales para la vivencia de nuestra identidad cristiana desde la íntima comunión con Cristo. Por eso, nos preguntamos: cuáles son los dinamismos soteriológicos presentes en este texto y cuáles son los campos semánticos que los significan? Cuál es el contenido y mensaje teológico dos dinamismos identificados?

\footnotetext{
${ }^{1}$ Pontificia Comisión Bíblica, La interpretación de la Biblia en la Iglesia, $7^{\text {a }}$ edición, Madrid: PPC Editorial y Distribuidora, 2001, p. 6

${ }^{2}$ El Método Semántico Teológico fue criado por dos profesores de la Pontificia Universidad Javeriana de Bogotá (Colombia) el Padre Pedro Ortiz, sacerdote jesuita, Doctor en Ciencias Bíblicas por el Pontificio Instituto Bíblico de Roma e la Doctora María Lucía de Zitzmann, Doctora en Teología Bíblica por la Pontificia Universidad Javeriana de Bogotá.
} 


\section{Determinación del Método}

Dado la novedad del Método Semántico Teológico aplicado a esta investigación, queremos en este apartado dar a conocer los fundamentos teóricos del método y esclarecer los componentes de su proceso analítico. Si el texto bíblico es ante todo un mensaje revelado para la salvación de la humanidad, es necesario identificar en ese texto vivo los elementos que aluden a la experiencia de salvación de Dios aconteciendo en la vida de los hombres y mujeres de la Biblia para un fundamento de la vida de fe de nuestras comunidades creyentes. En este sentido, el objetivo del método aplicado a este estudio consiste en

descubrir y analizar (..) las acciones salvadoras de Cristo en el contexto de los diversos campos semánticos que las significan. El método se construye de acuerdo con el aporte fundamental de la semántica, que pretende encontrar el sentido de los términos y de las distintas partes del texto que expresan una determinada acción, y con base en las distintas relaciones que lo conforman dentro de sus respectivos contextos. La manera de relacionar los términos es a través del campo semántico, muy diferente a la construcción de un análisis etimológico que se fija en el aspecto formal de las palabras y no tanto en su significado (..). El punto de partida es el análisis de las expresiones y de su significado ${ }^{3}$.

El Método Semántico Teológico, entre los distintos hermeneutas de los textos que conoce, cuenta con los aportes de Louw-Nida quien establece algunos principios básicos del análisis semántico que presentamos aquí de manera resumida: No existen sinónimos en el sentido de que dos campos semánticos no tienen el mismo significado en todos los contextos en los cuales se encuentran. Aun cuando dos campos semánticos no parecen ser distinguibles en su significación designativa o denotativa, ellos pueden ser distintos en su significación connotativa o asociativa. Las diferencias en el significado (de los campos semánticos) son marcadas por el contexto, textual o extra-textual. El significado de un campo se define por un conjunto de elementos distintos. Los significados figurativos son básicamente distintos con respecto a tres factores fundamentales: la diversidad de contextos, las

\footnotetext{
${ }^{3}$ Valvidieso Pedro Ortiz, S.J. y María Lucía Jiménez de Zitzmann, Análisis Semántico-Teológico del Nuevo Testamento, $1^{a}$ edición, Bogotá: Pontificia Universidad Javeriana, 2006, p. 55.
} 
diferencias a nivel de la conciencia (popular que existe) acerca de la relación entre el significado literal y figurativo, y el alcance del uso convencional. Los distintos significados de la misma palabra y los significados relacionados de palabras distintas, ambos, tienden a ser multidimensionales y son raras veces ortogonales en la estructura; es decir, que los distintos significados tienden a formar un modelo irregular de grupos en vez de estructuras ordenadas y bien organizadas ${ }^{4}$. Por ello, nuestro trabajo toma en consideración algunos núcleos problémicos que van orientando nuestra investigación:

¿Cuáles son las acciones soteriológicas de Cristo presentes en Ef 1, 3-6 que nos permiten, hoy en día, dar a conocer el núcleo de su mensaje salvifico para nuestra Iglesia? A esta pregunta se relaciona la siguiente: ¿cuáles son los campos semánticos relevantes que significan dichas acciones soteriológicas de Cristo presentes en este texto y con qué frecuencia aparece cada uno de ellos?

El primer paso del método consiste en una lectura sincrónica que permite identificar las acciones soteriológicas de Jesucristo, con sus respectivos campos semánticos en relación dinámica con las expresiones afines y las otras determinaciones que contribuyen a clarificar su sentido. La importancia de las expresiones opuestas, dentro de la dinámica del análisis lingüístico, consiste en que ellas, muchas veces, generan y enaltecen la dinámica soteriológica de la acción explícita.

El segundo paso del método, que surge del núcleo del primero, se encamina hacia un análisis diacrónico de los términos para su real comprensión y ubicación dentro del texto; así como también el análisis de las preposiciones que se encuentran expresando dichos dinamismos salvadores. Con esta base fundamental, entramos en dialogo, con distintos teólogos y exegetas, en el tercer paso del método, propiciando una hermenéutica teológica encaminada a esclarecer el sentido y significado de las acciones soteriológicas significadas y entretejidas, dentro de su propio y peculiar contexto. Este recorrido nos permite llegar al cuarto paso que consiste en la comprensión de nuestra propia realidad desde esta "nueva mirada" sobre el texto, para alcanzar una auténtica vivencia del mensaje salvífico en el hoy de nuestra vida cristiana.

\footnotetext{
${ }^{4}$ Cf. BibleWorks, Louw-Nida, Greek-English Lexicon of the New Testament base on Semantic Domains.
} 


\section{Lectura dos dinamismos soteriológicos presentes en el texto}

La respuesta a las preguntas hechas en el inicio de nuestro trabajo no puede darse solamente desde un análisis que contenga únicamente los cuatro versículos del Himno, objeto de nuestro estudio. Para conocer dichos dinamismos, faltaría ubicarlo y analizarlo dentro de su contexto literario del himno así como dentro del contexto total de la Carta. Ya que en el primer paso del Método aplicado, se sacan conclusiones novedosas que muestran desde el análisis que la comunión en y con Cristo, se encuentra abarcando la totalidad de la Carta y se presenta no sólo como su hilo conductor sino también como elemento fundamental del acontecer de Dios en la persona de Cristo para la comunidad creyente. Podemos apreciar los detalles de la lectura dos dinamismos soteriológicos en los siguientes cuadros ${ }^{5}$.

\section{Ef 1,3-4}

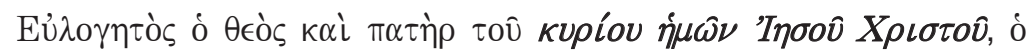

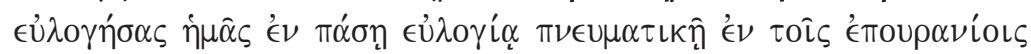

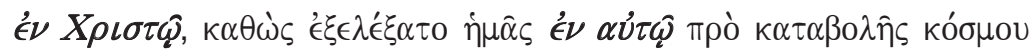

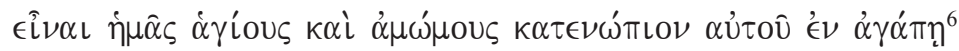

Bendito sea el Dios y Padre de nuestro Señor Jesucristo, que nos ha bendecido con toda clase de bendiciones espirituales, en los cielos, en Cristo; por cuanto nos ha elegido en él antes de la fundación del mundo, para ser santos e inmaculados en su presencia, en el amor

Relación soteriológica: Bendito sea el Dios y Padre de nuestro Señor Jesucristo, que nos ha bendecido con toda clase de bendiciones espirituales, en los cielos, en Cristo

Campos semánticos: Comunión $(2 \mathrm{x})$, bendición

\footnotetext{
${ }^{5}$ Por las condiciones exigidas para la publicación de este articulo, sólo hemos podido presentar los resultados del momento de Bendición y Filiación de Ef 1, 3-6, objeto de nuestro estudio para dar una idea clara y precisa del proceso que seguimos para todos los momentos soteriológicos tanto en el himno como en la carta en general.

${ }^{6}$ Observamos que en esta acción, Dios es llamado "Padre" no de nosotros sino de Jesús, quien a su vez, es reconocido como "Cristo" y "Señor" nuestro.
} 
Expresiones afines: Por cuanto nos ha elegido en él antes de la fundación del mundo, para ser santos e inmaculados en su presencia, en el amor; Predestinándonos para ser sus hijos adoptivos por medio de Jesucristo, según el beneplácito de su voluntad, para alabanza de la gloria de su gracia con la que nos agració en el Amado.

Otras determinaciones: En él tenemos por medio de su sangre la redención, el perdón de los delitos, según la riqueza de su gracia que ha prodigado sobre nosotros en toda sabiduría e inteligencia, dándonos a conocer el Misterio de su voluntad

Relación con Cristo: Mediación, comunión

Beneficiarios: los santos y fieles en Cristo Jesús

Contexto inmediato: El Plan divino de la salvación. EL Himno

Contexto amplio: El misterio de la salvación y de la Iglesia. Primera Sección de la Carta

\section{Ef 1, 3-4}

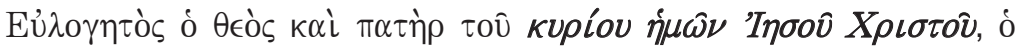

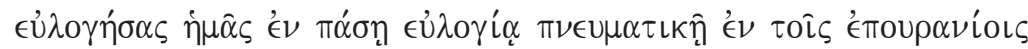

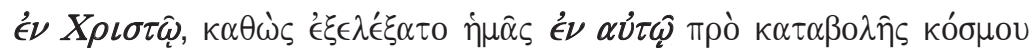

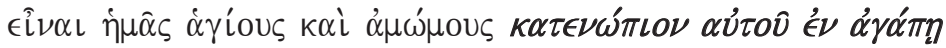

Bendito sea el Dios y Padre de nuestro Señor Jesucristo, que nos ha bendecido con toda clase de bendiciones espirituales, en los cielos, en Cristo; por cuanto nos ha elegido en él antes de la fundación del mundo, para ser santos e inmaculados en su presencia, en el amor

Relación soteriológica: Por cuanto nos ha elegido en él antes de la fundación del mundo, para ser santos e inmaculados en su presencia, en el amor 
Campos semánticos: Comunión, Elección, Santidad, Amor

Expresiones afines: Bendito sea el Dios y Padre de nuestro Señor Jesucristo, que nos ha bendecido con toda clase de bendiciones espirituales, en los cielos, en Cristo. Predestinándonos para ser sus hijos adoptivos por medio de Jesucristo, según el beneplácito de su voluntad; para alabanza de la gloria de su gracia con la que nos agració en el Amado.

Otras determinaciones: En él tenemos por medio de su sangre la redención, el perdón de los delitos, según la riqueza de su gracia que ha prodigado sobre nosotros en toda sabiduría e inteligencia, dándonos a conocer el Misterio de su voluntad

Relación con Cristo: Mediador, comunión

Beneficiarios: los santos y fieles en Cristo Jesús

Contexto inmediato: El plan divino de la salvación. El misterio de la salvación y de la Iglesia

\section{Ef 1, 3-4}

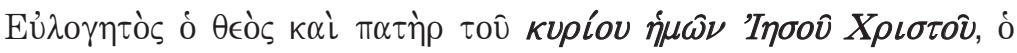

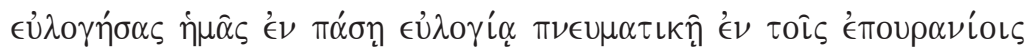

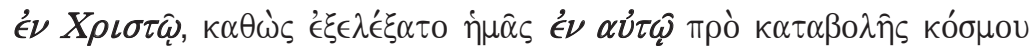

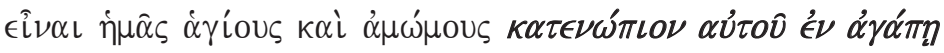

Bendito sea el Dios y Padre de nuestro Señor Jesucristo, que nos ha bendecido con toda clase de bendiciones espirituales, en los cielos, en Cristo; por cuanto nos ha elegido en él antes de la fundación del mundo, para ser santos e inmaculados en su presencia, en el amor

Relación soteriológica: Por cuanto nos ha elegido en él antes de la fundación del mundo, para ser santos e inmaculados en su presencia, en el amor

Campos semánticos: Comunión, Elección, Santidad, Amor 
Expresiones afines: Bendito sea el Dios y Padre de nuestro Señor Jesucristo, que nos ha bendecido con toda clase de bendiciones espirituales, en los cielos, en Cristo. Predestinándonos para ser sus hijos adoptivos por medio de Jesucristo, según el beneplácito de su voluntad; para alabanza de la gloria de su gracia con la que nos agració en el Amado.

Otras determinaciones: En él tenemos por medio de su sangre la redención, el perdón de los delitos, según la riqueza de su gracia que ha prodigado sobre nosotros en toda sabiduría e inteligencia, dándonos a conocer el Misterio de su voluntad

Relación con Cristo: Mediador, comunión

Beneficiarios: los santos y fieles en Cristo Jesús

Contexto inmediato: El plan divino de la salvación. El misterio de la salvación y de la Iglesia

\section{Ef 1,5-6}

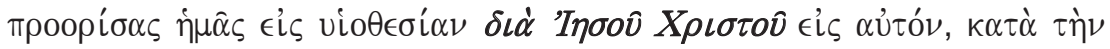

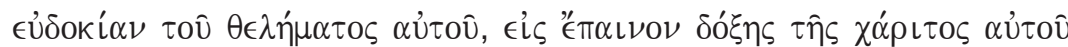

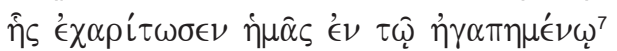

Eligiéndonos de antemano para ser sus hijos adoptivos por medio de Jesucristo, según el beneplácito de su voluntad, para alabanza de la gloria de su gracia con la que se agració en el Amado

Relación soteriológica: Predestinándonos para ser sus hijos adoptivos por medio de Jesucristo, según el beneplácito de su voluntad

Campos semánticos: Predestinación, Adopción, Voluntad, Comunión

\footnotetext{
${ }^{7}$ Podemos anotar que los beneficiarios de esta acción salvífica son llamados "hijos adoptivos" (de Dios) quien es el Padre nuestro $(1,2)$ y de nuestro Señor Jesucristo $(1,3)$. Jesús es presentado como "Cristo" y el "Amado".
} 
Expresiones afines: Bendito sea el Dios y Padre de nuestro Señor Jesucristo, que nos ha bendecido con toda clase de bendiciones espirituales, en los cielos, en Cristo. Por cuanto nos ha elegido en él antes de la fundación del mundo, para ser santos e inmaculados en su presencia, en el amor. Para alabanza de la gloria de su gracia con la que se agració en el Amado

Otras determinaciones: En él tenemos por medio de su sangre la redención, el perdón de los pecados, según la riqueza de su gracia que ha prodigado sobre nosotros en toda sabiduría e inteligencia, dándonos a conocer el Misterio de su voluntad. A Él por quien entramos en herencia, predestinados según el previo designio del que realiza todo, conforme a la decisión de su Voluntad

Relación con Cristo: Mediador

Beneficiarios: los santos y fieles en Cristo Jesús

Contexto inmediato: El plan divino de la salvación. El misterio de la salvación y de la Iglesia

\section{Ef 1,5-6}

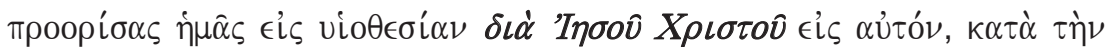

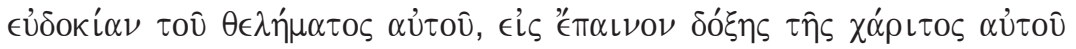

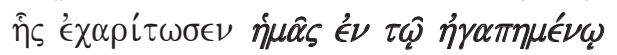

Eligiéndonos de antemano para ser sus hijos adoptivos por medio de Jesucristo, según el beneplácito de su voluntad, para alabanza de la gloria de su gracia con la que nos agració en el Amado

Relación soteriológica: Para alabanza de la gloria de su gracia en la que nos agració en el Amado

Campos semánticos: Gloria, Gracia, (Hijo) Amado, Comunión 
Expresiones afines: Bendito sea el Dios y Padre de nuestro Señor Jesucristo, que nos ha bendecido con toda clase de bendiciones espirituales, en los cielos, en Cristo. Por cuanto nos ha elegido en él antes de la fundación del mundo, para ser santos e inmaculados en su presencia, en el amor. Predestinándonos para ser sus hijos adoptivos por medio de Jesucristo, según el beneplácito de su voluntad. Según la riqueza de su gracia que ha prodigado sobre nosotros en toda sabiduría e inteligencia, dándonos a conocer el Misterio de su voluntad

Otras determinaciones: En él tenemos por medio de su sangre la redención, el perdón de los pecados... Hacer que todo tenga a Cristo por cabeza, lo que está en los cielos y lo que está en la tierra

Relación con Cristo: Mediador de la revelación del Padre en la gracia $y$ en el amor

Beneficiarios: los santos y fieles en Cristo Jesús

Contexto inmediato: El plan divino de la salvación. El misterio de la salvación y de la Iglesia

De la misma forma, la lectura sincrónica de la totalidad de la Carta, desde los dinamismos soteriológicos, fue un requisito fundamental para afirmar que la comunión en y con Cristo abarca la totalidad de la Carta. Su entretejido con los demás campos semánticos lo presenta como elemento fundamental para la vivencia de nuestra fe en Cristo. De esta manera, en la totalidad de la Carta, pudimos identificar 75 acciones de Cristo significadas por 86 campos semánticos de los cuales la comunión, que en ningún momento aparece como sustantivo dentro del texto, es dinamizada por preposiciones, atravesando la totalidad de la Carta con un total de 50 acciones. En el Himno, en el que se encuentra nuestro texto de estudio, identificamos 11 dinamismos soteriológicos de Cristo y 28 campos semánticos que los significan. El texto de nuestro estudio (Ef 1, 3-6), por su vez, contiene 4 dinamismos soteriológicos y 7 campos semánticos que los significan de los cuales la comunión aparece como siendo el campo más relevantes ( 5 veces).

En la perícope, los 4 "dinamismos soteriológicos" se manifiestan por "relaciones soteriológicas" en todos los versículos, no sólo a través del uso del 


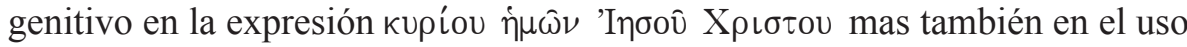
de la preposición '€́v que aparece en varios momentos dinámicos del texto (' $\epsilon \nu$

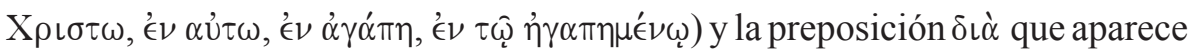
una vez en el texto ( $\delta\llcorner\grave{\alpha}$ 'I las "acciones soteriológicas" son determinadas por los verbos de movimientos. Pero, en nuestro texto no existen verbos que expresan determinadas acciones salvíficas ya que la presencia de un verbo en el texto no es necesariamente sinónimo de la presencia de una acción salvífica. En cambio, en nuestro texto se encuentran relaciones salvíficas de comunión-participación establecidas por el uso del genitivo y de las preposiciones indicadas. El acontecer salvífico se convierte en "dinamismo soteriológico" o "dinamismo salvífico" en la medida en que el acontecimiento no se queda fijado en un ponto estático sino que se extiende de manera continua y permanente en el panorama semántico del texto. Ese dinamismo abarca el texto en sus diferentes personajes así como el autor y el lector unidos por el vinculo de la pre-comprensión de la fe.

\section{Dinámica preposicional como expresión del campo semántico de la Comunión}

Los resultados de este primer paso nos permiten, en este segundo paso, buscar el sentido y el significado de los términos claves de nuestra investigación que en este caso se trata de la Comunión. Para analizar este campo semántico,

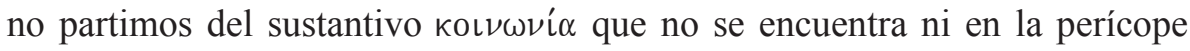
estudiado ni en la Carta en general. Partimos de la fórmula év Xpı $\sigma \tau \omega$ y sus derivados, que se encuentran de manera frecuente en el texto, manifestando la comunión del creyente en y con Cristo. Una breve lectura de la Biblia desde la perspectiva de ese campo semántico nos proporciona elementos informativos importantes de la Comunión. En el AT, de manera paralela al sustantivo

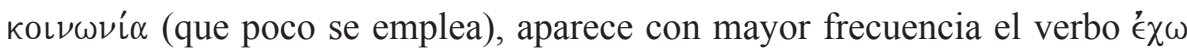
"tener", (y sus derivados), que manifiesta la idea de una pertenencia. Mientras que el verbo '́ $\chi \omega$ 'tener', y específicamente su compuesto $\mu \in \tau \in$ '́ $\chi \omega$ 'participar', aluden más bien a los individuos que gozan de la posesión de un bien o al hecho

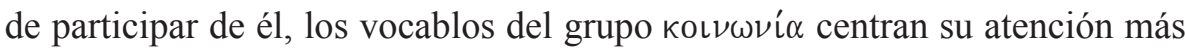
en lo común y sólo en un segundo momento se refieren a los individuos que participan de ello. El hecho de que la solidaridad no consiste únicamente en un tener, sino que exige también una participación activa, una colaboración, lo

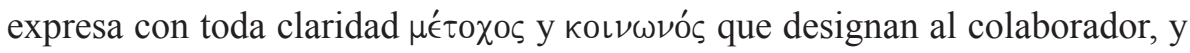




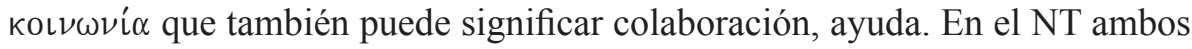
grupos de vocablos son empleados sobre todo al hablar de la relación del hombre con Dios o con poderes sobrehumanos ${ }^{8}$.

Se encuentran también en el NT, distintas expresiones de la comunión. Cabe señalar que los campos semánticos, especialmente en Pablo, además de expresarse a través de sustantivos, pueden ser representados por verbos, adverbios y también por preposiciones. Fitzmyer reconoce que la última unión de Cristo y los cristianos se expresa mediante una serie de intensas fórmulas preposicionales y también mediante la metáfora cuerpo de Cristo. Pablo emplea principalmente cuatro preposiciones con el nombre de "Cristo" como complemento para indicar distintas facetas del influjo de Cristo en la vida del cristiano. El uso de cada una de estas preposiciones es variado y, con frecuencia,

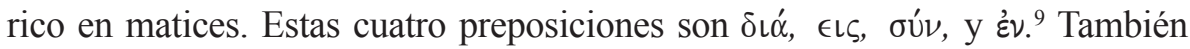
en el vocabulario neotestamentario, la comunión se expresa en algunos casos por el uso del dativo y del genitivo. A través del dativo se indica generalmente a la persona con la que somos "partícipes" o de la que somos "compañeros".

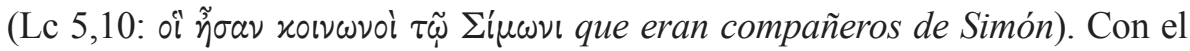
genitivo se indica en que somos "compañeros" o de quien somos "compañeros". Es el caso del v. 3 de la perícope que manifiesta una profunda relación de comunión no sólo entre Dios Padre y su Hijo Jesús Cristo más también entre Jesús y los

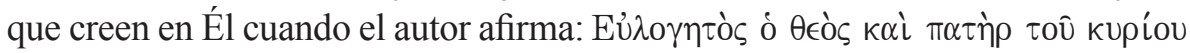

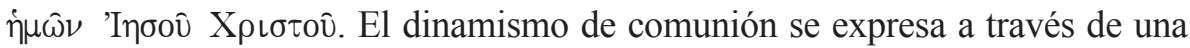
relación de pertenencia del creyente a Cristo. Cabe señalar que las preposiciones indicadas no significan siempre la comunión sino en los casos señalados en nuestra investigación. Por eso, la preposición $\epsilon \iota \varsigma$, que no aparece en nuestro texto, puede también referirse a una relación en un sentido neutro u hostil. La preposición oúv no aparece ni en nuestra perícope ni en el Himno, pero aparece de manera abundante en la Carta con un radical o con verbos compuestos. En

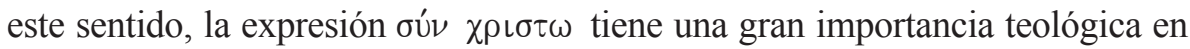
Pablo para mostrar no sólo el sentido de la vida presente "con Cristo" sino también el sentido escatológico. El uso de la preposición “ $\epsilon \nu$ ” con nombres o títulos, es muy frecuente en Pablo y en la Carta a los Efesios para manifestar la comunión con Dios, con Cristo y entre los creyentes como podemos ver en las

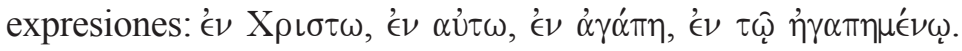

\footnotetext{
${ }^{8}$ Cf. J. Eichler, "Solidaridad ( $\left.€ \chi \omega\right)$ " en L. COENEN, E. Beyreuther y H. Bietenhard, Diccionario Teológico del Nuevo Testamento, Vol. 2, 4 edición, p. 670.

${ }^{9}$ Cf. Joseph A. Fitzmyer, Teología de San Pablo, Sintesis y Perspectivas, p. 166.
} 
La preposición $\delta i ́ \alpha$ se refiere generalmente a un medio por el cual sucede algo. En la literatura neotestamentaria "su campo de aplicación con régimen de acusativo se limita al ámbito causal; pero, con régimen de genitivo, su campo se amplia para abarcar el del dativo instrumental. Además, esta preposición adopta construcciones hebreas ( $\delta$ í $\alpha$ con infinitivo o con acusativo e infinitivo) y forma combinaciones de palabras"10. Con el genitivo, esta preposición puede tener tanto un sentido espacial, por, por medio de, a través de, como expresar un sentido temporal de toda la duración en el tiempo, a lo largo de, durante; puede traducir también un período de tiempo dentro del que sucede algo, mientras, en. La preposición sí $\alpha$ puede referirse también a un mediador. En este caso puede expresarse con el genitivo de persona o de causa, el instrumento; e acompañado con un verbo puede designar la manera. Ese segundo paso, que surge del núcleo del primero, se encaminó hacia un análisis de la Comunión para su real comprensión y ubicación dentro del texto; así como también la lectura de las preposiciones que se encuentran expresando dichos dinamismos salvadores. Ahora, si la comunión es hilo conductor y fundamento soteriológico del texto, ¿Cuál es su contenido y mensaje teológico en cada una de las acciones que se encuentra significando en dicho texto? ¿Podríamos evidenciar a través del análisis que la comunión es el principio de identidad de la vida cristiana? ¿Los resultados de esta investigación nos podrían ayudar a una fundamentación de la vida cristiana hoy?

\section{Interpretación teológica de los dinamismos soteriológicos}

Con base de los pasos anteriores, entramos en dialogo, con otros comentaristas, en el tercer paso de nuestro Método. El propósito es propiciar una hermenéutica teológica encaminada a esclarecer el sentido y significado de las acciones soteriológicas. Dichas acciones son significadas y entretejidas dentro de su propio y peculiar contexto con una variedad de campos semánticos. En el momento dinámico de Elección y Filiación (Ef 1,3-6), texto de nuestro estudio, identificamos 4 acciones salvíficas de Cristo (ver cuadros encima) y 7 campos semánticos (Bendición, Elección, Santidad, Amor, Predestinación, Adopción, Voluntad) que se entretejen con la comunión. La dinámica preposicional (expuesta en el apartado anterior) que abunda en el texto enfatizando la figura de Cristo e sus derivados nos muestra que Cristo

${ }^{10}$ A. J. Heb, “סı́’”, en H. Balz y G. Schneider, Diccionario Exegético del Nuevo Testamento, Vol. 1, p. 894. 
Jesús no puede ser simplemente un sujeto pasivo sino un protagonista esencial del acontecer de la salvación divina. Dios nos bendice en Él y por Él (Ef 3-5).

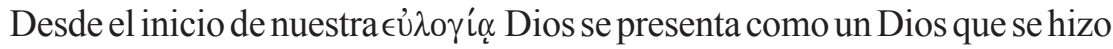
cercano bendiciéndonos en la persona de Cristo con toda clase de bendiciones espirituales. Este Dios que bendice, debe a su vez, ser bendito. Es decir, si el ser humano es bendecido por Dios en Cristo, a su vez debe bendecir a Dios en Cristo como respuesta a la bendición divina. La bendición de Dios a favor de la humanidad acontece en la persona de Cristo como mediación y centro de todos los acontecimientos que tienen que ver con ella. Por otra parte, esta bendición

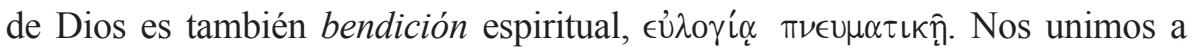
Schleir para observar que "las palabras terminadas en ıкós designan en general, lo que pertenece al concepto del que se derivan, lo que lleva su índole, lo que es de su esencia. La bendición de Dios es de la misma índole que el Pneûma, deriva del Pneûma su manera de ser (...) La bendición es algo que se revela en el Pneûma, porque se da en él y está presente en él. El beneficio de la bendición se hace accesible para nosotros en el Pneûma, es el beneficio que el Pneûma nos concede en sí mismo. En el Pneûma se nos han dado todos los bienes y dones, porque se contienen en él y vienen sobre nosotros con la bendición de Dios. En él se nos abren, se hacen conocibles y asequibles para nosotros"11.

La acción del Espíritu acontece en la vida del creyente por mediación de Cristo y de su comunión con él. El término bendición aparece tres veces en este

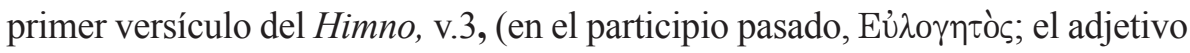

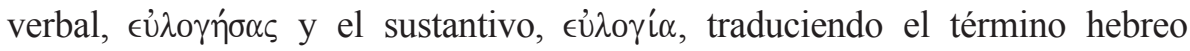
'berakah' del verbo 'barak' que significa no sólo bendecir y alabar pero también arrodillarse, como respuesta humana a la acción divina. Desde esta perspectiva, la bendición es ante todo una actitud de adoración a Dios, ponerse de rodillas ante Él, para alabarlo y bendecir su santo nombre. Esta bendición nos pone en comunión con un Dios Trino, el Dios Padre de nuestro Señor Jesucristo en unión con el Espíritu Santo. Nuestro objeto de estudio se concentra explícitamente en el campo semántico de la Comunión, que se encuentra significando la acción soteriológica del Hijo a través de la totalidad de la Carta como hilo conductor de la misma. Sin embargo, se hace necesario, para la comprensión de dicho campo semántico, relacionarlo con el entretejido textual, de otros campos que contribuyen de modo definitivo a darle el verdadero sentido que contiene en cada una de las acciones por ellos significadas.

${ }^{11}$ Schlier, Heinrich, Carta a los Efesios: Comentario. Salamanca: Sígueme, 1991, p. 56. 
La primera acción soteriológica (v.3), de comunión entre Cristo, su Padre y "nosotros", se expresa una vez más con el uso del genitivo griego tov̂ kupíou $\dot{\eta} \mu \omega \hat{\omega}$ que en la traducción española se expresa con la preposición 'de'Jesucristo. La segunda (v.4) se traduce con la preposición 'en él', 'év $\alpha \cup \hat{\imath} \omega$ '. La tercera (v.5)

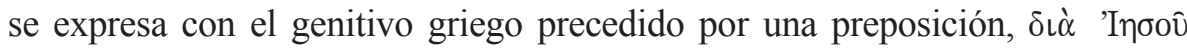

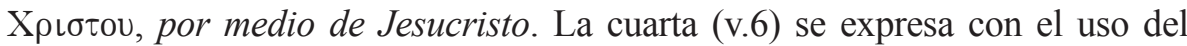

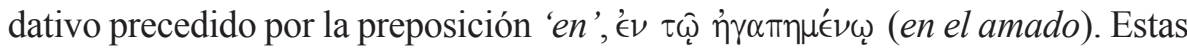
relaciones activas, en las que Dios Padre es el agente soteriológico, manifiestan una profunda comunión con la persona de Jesús. En la interpretación de estos versículos, Boismard enfatiza de manera excluyente la acción del Padre, en cuanto agente de la bendición, de la elección y de la adopción ${ }^{12}$. El, Dios Padre es quien nos da la posibilidad de participar en su designio salvífico. Sin embargo, no podemos entender esta acción del Padre, en toda su riqueza y profundidad, independientemente de su Hijo Jesucristo quien, en comunión con Él y con su Espíritu, realiza sus designios, vinculando a dicha comunión a la comunidad creyente que unida en su Fe, profundamente trinitaria, realiza desde y en Cristo, como beneficiaria del designio salvífico, una misión soteriológica, constituyéndose al mismo tiempo, en beneficiaria de todas las bendiciones.

Las bendiciones de Dios, de las que somos beneficiarios, acontecen en medio de la comunidad de los creyentes por medio de Jesucristo: "Bendito sea el Dios y Padre de nuestro Señor Jesucristo, que nos ha bendecido con toda clase de bendiciones espirituales, en los cielos, en Cristo" (v.3). Cuando el autor habla de "nosotros", en las expresiones "nuestro Señor Jesús Cristo" y "nos ha bendecido", tanto en este versículo como en la totalidad de la Carta, nos llama la atención el empleo de esta primera persona del plural, y podemos preguntarnos: a quién se dirige esta bendición del Padre a través de esta expresión? Es importante hacer unas aclaraciones respecto a este pronombre que contrasta al final del Himno con la aparición de la segunda persona del plural, "vosotros". A propósito, Michel Bouttier, afirma que en múltiples ocasiones, "los problemas de crítica textual o de exegesis, llamaron la atención sobre el manejo del pronombre personal en la Carta (...) El pronombre "vosotros" no presenta dificultades ya que se dirige a los destinatarios. Pero ¿quién se oculta tras el pronombre "nosotros"? (...) cuatro respuestas posibles: el "nosotros" comunitario que incluye a todos los creyentes. El "nosotros" epistolar que incluye a Pablo y a sus posibles colaboradores. El "nosotros" apostólico que Pablo emplea apoyándose

${ }^{12}$ Cf. Boismard, M., E., L'Enigme de la lettre aux Ephésiens, Paris: Gabalda et C ${ }^{\mathrm{ie}}, 1999$ p. 20. 
en la autoridad de los apóstoles. Y el "nosotros" personal, es decir, un "yo" enfatizado que se utiliza a veces en las cartas oficiales. La Carta a los Efesios nos lleva a pensar en el uso de un "nosotros" que incluye a los cristianos de origen judío para distinguirlos de los destinatarios de la Carta dirigida a una comunidad pagano-cristiana. Este doble sentido sería la clave para entender no sólo el capítulo dos sino también el Himno"13.

Además, siendo nuestro Himno una bendición, podemos resaltar en su dinámica, el paso inter-actuante de un aspecto esencialmente celebrativo, que enfatiza la dimensión comunitaria "nosotros" y la exhortación del autor a sus destinatarios que enfatiza el "vosotros". Desde esta perspectiva, al inicio de nuestro Himno, no es el autor quien entra de manera exclusiva en la celebración de las bendiciones de Dios sino que toda la comunidad es la que bendice a Dios por habernos bendecido en Cristo; manifestando así, la comunión entre los miembros de la comunidad, una comunión fundamentada en la persona de Jesús. La bendición de Dios nos llega en Cristo, desde nuestra comunión en y con él. Aunque Dios Padre sea el agente salvífico de estas bendiciones espirituales, podemos afirmar, que Cristo Jesús, en este caso, no puede ser simplemente un "sujeto pasivo". Dios nos bendice en él y por él. Por ello, la relación de Cristo con los beneficiarios de esta bendición, es no sólo una relación de mediador sino también de comunión activa. El dinamismo de comunión con Cristo es el que nos otorga la bendición. Los santos y fieles que vuelven a aparecer como beneficiarios de esta bendición de Dios nos comunican el significado de la expresión afín (v 4-5) que hace aun más inteligible la cuarta acción soteriológica.

Podemos observar en la dinámica del texto, que la expresión é $\nu$ X $\rho\llcorner\tau \hat{\emptyset}$

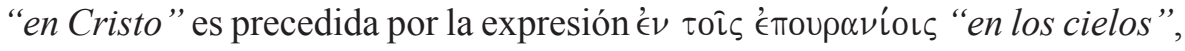
ambas expresiones se encuentran fundamentalmente relacionadas. Las bendiciones espirituales con las que Dios nos ha bendecido acontecen "en los cielos" y "en Cristo". Esta expresión empleada frecuentemente en la Carta a los Efesios, con distintas variaciones, es muy significativa para el autor, manifestando así lo que "es del cielo", o más bien "lo que pertenece al mundo

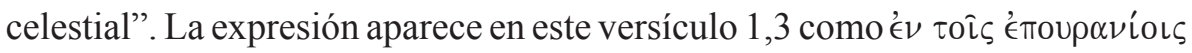

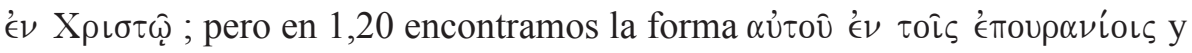

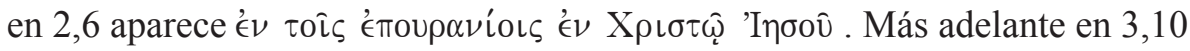

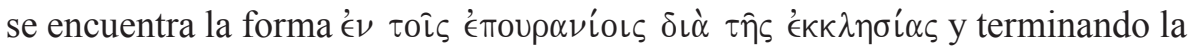

\footnotetext{
${ }^{13}$ Bouttier, Michel, L'épître de Saint Paul aux Éphésiens, Genève: Labor et Fides, 1991 p, 291.
} 


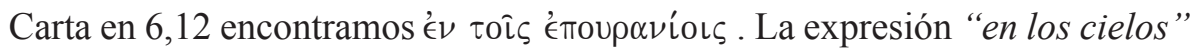
aparece no sólo en relación con Cristo sino también en relación con la Iglesia y con las potestades. En la persona de Cristo, la bendición de Dios nos abre un espacio en el cielo y el cielo se encuentra en nuestra vida. Esto significa que para el creyente, lo inmediato, lo contingente, las cosas y realidades que conforman su existencia adquieren otra dimensión, la dimensión divina que trasciende e impregna de sentido y de luz la realidad prosaica de la existencia humana. Es decir, que el que vive en comunión con Cristo permite que el cielo acontezca ya en él y en la realidad que lo rodea. En comunión con Cristo, dentro de la Iglesia, el creyente ya está en los cielos y recibe una fuerza, un poder para entrar en medio de las Potestades celestiales.

Por otra parte, la comunión con Cristo, que es fuente de estas bendiciones espirituales, hace posible no sólo nuestra elección divina, para ser santos e inmaculados en su presencia, en el amor sino también nuestra predestinación para ser hijos adoptivos de Dios (v.4). Esto quiere decir, que si Dios nos ha bendecido "en los cielos" y "en Cristo", esta bendición se entiende, en el caso presente, desde el dinamismo salvador de la elección y de de la predestinación que la determinan y la concretizan, entretejiéndose con los campos semánticos de la santidad y del amor. Dicha elección (v.4) y predestinación (v.5) se convierten también en campos semánticos significantes de las siguientes acciones soteriológicas que expresan la identidad comunitaria de los destinatarios; por cuanto nos ha elegido en él antes de la fundación del mundo para ser santos e inmaculados en su presencia (v.4), y predestinados para ser sus hijos adoptivos en la persona de Cristo (v.5). La comunión con Cristo es, entonces, el lugar referencial e imprescindible para que el dinamismo salvador de la bendición, de la elección y de la predestinación acontezca en la vida de los creyentes para ser santos e inmaculados en el amor.

Ser santos e inmaculados se refiere tanto a la humanidad genéricamente, como a la comunidad de los creyentes, específicamente. Por eso, estos campos semánticos vuelven a aparecer para tratar del amor de Cristo por su Iglesia dentro de un contexto de relación conyugal:

Maridos, amad a vuestras mujeres como Cristo amó a la Iglesia y se entregó a sí mismo por ella para santificarla, purificándola mediante el baño del agua, en virtud de la palabra, y presentársela resplandeciente a sí mismo; sin que tenga mancha ni arruga ni cosa parecida, sino que sea santa e inmaculada (Ef 5,25-27). 
Michel Bouttier destaca la asociación de la elección con sus consecuencias finales y enfatiza a continuación el resultado de la redención ${ }^{14}$ como esfuerzo humano para responder a la gracia divina. Sin embargo, esta interpretación es totalmente contraria a nuestra manera de ver el texto. Ser "santos e inmaculados" en la presencia de Dios, no es ante todo el resultado de una ética en la vida, sino fruto de la gracia de la elección que nos hace nuevas creaturas en Cristo. La elección divina ya es una obra de la gracia, una actuación de la misma. Ser "santos e inmaculados en su presencia en el amor", determina nuestra pertenencia y nuestra identidad en Dios cuya esencia es el Amor. Dios nos ha elegido para estar con y en Él, en su presencia, porque el Dios Santo es el Dios del Amor.

Esta elección divina antes de la fundación del mundo y la predestinación para ser sus hijos adoptivos en Cristo, acontecen en la vida de los creyentes según el beneplácito de la voluntad de Dios. La elección divina no es ni una exclusión ni una selección. El motivo teológico de la elección y de la predestinación consiste en la revelación de este designio de Dios que actúa según el beneplácito de su voluntad y en comunión con su Hijo Jesucristo. En relación con la santidad y el amor, este dinamismo salvador de elección y de predestinación se entreteje aquí, con el campo semántico de la Voluntad divina, que recoge todo el dinamismo del texto, desde el inicio, para enfatizar la gratuidad de este don Divino.

Este recorrido nos proporciona una comprensión de nuestra propia realidad desde esta "nueva mirada" sobre el texto, para alcanzar una auténtica vivencia del mensaje salvífico en el hoy de nuestra vida cristiana. Uno de los aspectos fundamentales del objetivo de nuestro estudio es el de comunicar las consecuencias transformadoras de esta investigación con respecto a la realidad actual, ya que investigar, comprender, interpretar y comunicar son las funciones fundamentales de nuestro método como medio para acercarnos al texto bíblico. Nos unimos a Bernard Lonergan para reconocer que la función de la comunicación "es de un interés capital, porque en esta etapa final es donde la reflexión teológica aporta todo su fruto"15. Desde el inicio de la Carta, la comunión con Cristo aparece revelando no sólo la identidad de Cristo sino también nuestra propia identidad cristiana; es decir, nuestro ser y nuestro vivir en Cristo. El Misterio de Dios que nos da a conocer el autor de la Carta y

\footnotetext{
${ }^{14}$ Michel Bouttier, L'épître de Saint Paul aux Éphésiens, Genève, p, 63.

${ }^{15}$ Bernard Lonergan, Método en Teología, 4a edición, Salamanca: Ediciones Sígueme, 2006, p. 341.
} 
nos invita a celebrar, es ante todo, el misterio de nuestra propia identidad. La afirmación de dicha identidad cristiana frente a tantas ideologías, corrientes e invitaciones de nuestro mundo y de nuestras propias estructuras eclesiales, muchas veces obstaculizadoras del acontecer del mensaje del evangelio de Cristo en nosotros, exige desde su realidad la profesión y legitimación explícita de nuestra fe. Esta identidad desde la perspectiva nuestro texto no se afirma ante todo, como se considera con frecuencia hoy, pertenencia a una institución eclesial sino pertenencia a Cristo y a su Evangelio. El ser cristiano no es primero un asunto de denominaciones eclesiales - católico, evangélico, ortodoxo, luterano - sino un ser discípulo y apóstol de Jesucristo.

En el Saludo inicial, el autor al presentar a sus destinatarios, los llama, “santos y fieles en Cristo Jesús” (1,1). En 3,4, el autor reconoce que Dios nos ha elegido en Cristo para ser santos e inmaculados en su presencia, en el amor. ¿Cómo podemos entender que los cristianos sean llamados santos? La concepción de la santidad hoy está estrechamente vinculada con la de la perfección, entendiéndola como una vida sin pecado. Una concepción que no sólo hace perder el sentido de la santidad sino que va haciendo del ideal cristiano de la configuración con Cristo, un ideal inalcanzable, dejando terribles vacíos y consecuencias nefastas en el proceso de apropiación y vivencia del mensaje revelado. Los cristianos como santos y fieles en Cristo, no son personas perfectas, eximidas de todo pecado sino pecadores llamados por Dios en Jesucristo a permanecer en Él, a emprender un largo camino de conversión y de vida interior para una existencia contraria a los valores efímeros del mundo actual en el que deben estar plenamente presentes $y$ totalmente presentes en Cristo. El cristiano está llamado a vivir plenamente la realidad humana desde su plena comunión con Cristo.

La santidad es una característica muy importante de la Iglesia como cuerpo de Cristo. Cristo murió 'para consagrarla a Dios, purificándola por medio del agua y la palabra. Se preparó así una iglesia esplendorosa, sin mancha ni arruga ni cosa parecida; una iglesia santa e inmaculada' (Ef 5, 27). Los dos se unen en una sola carne $(5,31-32)$, de modo que la santidad de Cristo puede percibirse en su Iglesia, Cuerpo suyo que está siendo edificado en el amor $(4,6)^{16}$. Es decir que es posible vivir una plena comunión con Cristo y es posible vivir en la santidad, desde nuestra elección en el mismo Cristo Jesús. Por eso, afirmamos con Raymond Brown que "los

\footnotetext{
${ }^{16}$ Cf. Raymond Brown, Las Iglesias que los Apóstoles nos dejaron, $4^{\mathrm{a}}$ edición, Bilbao: Descleé de Brouwer, 1998, p. 68.
} 
escándalos e insensateces institucionales, incluso en los niveles más altos, no desmoralizarán (...) En el credo apostólico confesamos 'creo en la santa iglesia católica'. Mientras exista esta fe, la iglesia perdurará a pesar de la ineficacia de su administración"17.

\section{Conclusión}

Los cuatro pasos metodológicos nos ayudaron a evidenciar, interpretar, comprender y comunicar a nuestros lectores el contenido dinámico y salvífico que el autor de la Carta quiso dar a conocer a sus destinatarios bajo el requerimiento de la vida de comunión con Cristo. Esta perícope del Himno a los Efesios invita a los cristianos hoy a volver a descubrir el verdadero sentido de la comunión con Cristo a la que están llamados, no como algo lejano sino como un aspecto constitutivo de nuestra identidad cristiana. La legitimación de nuestra fe, en el sentido de dar razón de la esperanza que llevamos en nosotros, debe necesariamente pasar por una crítica y apropiación del lenguaje cristiano que se fundamenta en la vivencia de dicha Palabra de la Verdad, el Evangelio de la Salvación. La imagen de la comunión que nos revela el texto desde nuestra elección en Cristo y el Misterio de Dios que se nos da a conocer, no es un pretexto para esconder nuestros errores, hipocresías y escándalos. En un mundo marcado por el materialismo y la pérdida de identidad, aún se encuentran personas sedientas de Dios, que lo buscan en las 'noches' de sus vidas. Para ellas, esta "nueva mirada" sobre el texto bíblico con los resultados que nos ha brindado, puede ser un despertador y una fuerza esperanzadora que calme su sed de salvación.

\section{Referencias bibliográficas}

BIBLIA DE JERUSALÉN, Bilbao: Desclée de Brouwer, 1975.

BROWN Raymond, Las Iglesias que los Apóstoles nos dejaron, 4ª edición, Bilbao: Descleé de Brouwer, 1998.

LONERGAN Bernard, Método en Teología, $4^{\text {a }}$ edición, Salamanca: Ediciones Sígueme, 2006.

${ }^{17}$ Raymond Brown, Las Iglesias que los Apóstoles nos dejaron, p. 74. 
LOUW Johannes and NIDA Eugene, Greek-English Lexicon of the New Testament. Base on Semantic Domains, Second Edition, Vol. 1, New York: United Bible Society, 1988/1989.

NESTLE-ALAND, Greek-English New Testament, U. S. A, Deutsche Bibelgesellschaft, 2001.

ORTIZ VALVIDIESO Pedro, S.J. y María Lucía Jiménez de Zitzmann, Análisis Semántico-Teológico del Nuevo Testamento, $1^{a}$ edición, Bogotá: Pontificia Universidad Javeriana, 2006.

PONTIFICIA COMISIÓN BÍBLICA, La interpretación de la Biblia en la

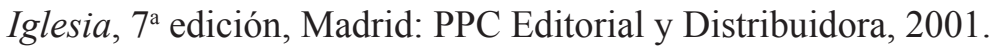

SCHLIER Heinrich, La Carta a los Efesios, Salamanca: Ediciones Sígueme, 1991.

Joseph Théophile Ngouo, M.S.A. Doutorando em Teologia Bíblica pela PUC-Rio Mestre em Teologia Bíblica pela Pontificia Universidad Javeriana de Bogotá-Colombia Rio de Janeiro / RJ - Brasil E-mail: josefteofil@yahoo.fr

Recebido em: 16/07/14 Aprovado em: 17/09/14 